\title{
TRABALHO DOCENTE NA EDUCAÇÃO BÁSICA: AS CONDIÇÕES E A JORNADA DE TRABALHO NA EDUCAÇÃO FÍSICA NA EDUCAÇÃO DE JOVENS E ADULTOS TRABALHADORES NO MUNICÍPIO DE BELÉM DO PARÁ1
}

Maria da Conceição dos Santos Costa²

\begin{abstract}
Resumo
Este estudo analisa a configuração do trabalho docente em Educação Física na Educação de Jovens e Adultos a partir das condições e jornada de trabalho materializadas na Educação Básica do Município de Belém - Pará. A pesquisa foi realizada com oito docentes da Rede Municipal de Ensino e fundamentada na teoria crítica dialética. As condições e jornada de trabalho têm se caracterizado como aspectos que medeiam a configuração de um trabalho precário e intensificado na escola pública. Ao mesmo tempo, os docentes resistem e apontam a relevância da EF para a formação dos jovens e adultos trabalhadores.
\end{abstract}

Palavras-Chave: Trabalho Docente. Educação Física. Educação de Jovens e Adultos.

\begin{abstract}
This study analyzes the configuration of the teaching work in Physical Education in Youth and Adult Education from the conditions and day-work materialized in the Basic Education of the Municipality of Belém - Pará. The research was carried out with eight teachers from the Teaching Municipal Network and based on critical dialectical theory. The conditions and Day-work have been characterized as aspects which mediate the configuration of precarious and intensified work in the public school. At the same time, teachers resist and point out the relevance of Physical Education to forming young and adult workers.
\end{abstract}

Key-Words: Teaching Work. Physical Education. Young and Adults Education.

\section{Introdução}

Nos últimos anos têm avançado no Brasil os estudos sobre trabalho docente (OLIVEIRA, 2010; DUARTE, 2011; KUENZER e CALDAS, 2009) enquanto uma categoria central para compreensão dos processos de trabalho dos

\footnotetext{
${ }^{1}$ DOI: https://doi.org/10.22409/tn.16i29.p4558

2 Doutora em Educação (PPGED/UFPA). Instituto de Ciências da Educação. Faculdade de Educação Física. Grupo de Estudo e Pesquisa em Educação do Campo na Amazônia (Geperuaz). E-mail de contato: concita.ufpa@gmail.com
} 
docentes que atuam na educação básica mediante as mudanças provocadas no campo da organização e gestão da educação, oriundas das reformas educacionais no Brasil.

De acordo com Oliveira e Vieira (2012), no Brasil a discussão sobre as condições e jornada de trabalho tem sido integrada aos assuntos sobre a valorização dos profissionais da educação, tema de grande atualidade para o conjunto do movimento docente no país.

É nesse contexto que essa pesquisa se insere e tem como centro de discussão o trabalho do docente de Educação Física (EF) que atua na Educação de Jovens e Adultos (EJA) na Rede Municipal de Ensino de Belém-PA (RMEB). Nessa direção a partir de um recorte realizado, este estudo foi norteado pela seguinte questão: como se configura o trabalho do docente de EF que atua na EJA na RMEB a partir das condições e jornada de trabalho materializadas na educação básica, na realidade concreta do Município de Belém do Pará?

Esse debate nos instiga a pensar sobre o trabalho docente em EF na EJA como campo de discussão desafiador, marcado por contradições, resistências, possibilidades e lutas que os trabalhadores da EF experienciam na escola pública. Partindo desse entendimento, nosso objetivo foi analisar a configuração do trabalho do docente de EF que atua na EJA a partir das condições e jornada de trabalho materializadas na educação básica, na realidade concreta do Município de Belém do Pará.

Para compreender a complexidade das condições e a jornada de trabalho dos docentes dessa modalidade de educação, optamos por utilizar a entrevista semiestruturada como instrumento de coleta de dados envolvendo 8 professores de EF da educação básica, atuantes na EJA da RMEB. Ressaltamos que, aqui, empregaremos nomes fictícios aos sujeitos docentes para resguardar sua identificação e atender aos princípios éticos exigidos às pesquisas com seres humanos.

O tratamento dos dados foi realizado tomando como base a técnica de análise de conteúdo (BARDIN, 2011), o processo analítico também foi fundamentado à luz das ideias de autores do campo da teoria crítica dialética.

Organizamos o texto em três momentos nos quais abordaremos o trabalho docente em EF na EJA, as condições e jornada de trabalho destes trabalhadores na RMEB e as considerações finais.

TrabalhoNecessário- www.uff.br/revistatrabalhonecessario: ano 16, №29/2018 


\section{Trabalho docente em EF na Educação de Jovens e Adultos trabalhadores}

O mundo do trabalho tem sido marcado nas últimas décadas por fortes e profundas mudanças. A exploração do trabalhador pelo trabalho tem sido um campo fundamental para a lógica de perpetuação do sistema capitalista. De acordo com Harvey (2014), o trabalho é um dos aspectos centrais que alarga o campo lucrativo capitalista pela sua forma de controle do trabalho, pela remuneração e pelos processos de trabalho no modo de produção do capital, hegemonicamente.

Contraditoriamente, ainda que condicionado pelas estruturas sócioprodutivas do capital, o trabalho é uma atividade que faz parte da construção histórica da humanidade. Por meio do trabalho, o homem se constitui enquanto ser social e histórico diante dos processos que realiza com a natureza. Encontramos em Marx (2013) o sentido de trabalho que traduz a raiz do modo como os seres humanos produzem a si mesmos. Ele traz o sentido ontológico do trabalho:

Antes de tudo, o trabalho é um processo entre o homem e a natureza, um processo em que o homem, por sua própria ação, medeia, regula e controla seu metabolismo com a natureza. Ele mesmo se defronta com a matéria natural como uma força natural (MARX, 2013, p. 31-32).

O trabalho é uma atividade fundante da existência humana e por ele o homem vai se construindo diante da relação com a natureza e com os demais sujeitos sociais. Frigotto (2010) salienta que é no próprio processo histórico de tornar-se humano que surge a atividade que denominamos de trabalho como algo específico do homem.

Sobre a compreensão do trabalho docente em EF na EJA, nosso entendimento é de que este é uma categoria que parte da totalidade do trabalho e que possui relações com o modo de produção do sistema capitalista. Ressaltamos que o trabalho docente integra a totalidade constituída pelo trabalho no capitalismo, no qual se submete à lógica e às contradições sociais do capital (DUARTE, 2011).

TrabalhoNecessário- www.uff.br/revistatrabalhonecessario: ano 16, №29/2018 
O trabalho constitui-se em ato de transformação da natureza pelo homem para sua própria sobrevivência, o que resulta também e, ao mesmo tempo, na transformação do homem pelo trabalho. É possível considerar que o trabalho é detentor de um caráter educativo. Educação e trabalho são elementos fundamentais da condição humana, indispensáveis à socialização e determinantes de nossas experiências (OLIVEIRA, 2010).

Nessa mesma direção, Kuenzer e Caldas (2009, p. 22) ressaltam que o trabalho é parte da totalidade constituída pelo trabalho no capitalismo, mas que é submetido à sua lógica e contradições. Isto representa dizer que "o trabalho docente não escapa à dupla face do trabalho: produzir valores de uso e valores de troca".

Para produzir valores de uso no processo de trabalho, a atividade do homem realiza uma transformação sobre o objeto de sua ação, subordinada a um determinado fim: a realização de um produto ou de um serviço para atender as necessidades humanas. Uma parte da natureza será adaptada às necessidades do homem por meio da mudança de sua forma. Esse processo não tem como finalidade produzir excedentes para acumular riqueza (id., ibid., p. 22).

As autoras destacam que, sob a égide do capitalismo, a característica do processo de trabalho passa a ser a produção de valor de troca, valor que se autoexpande, com a finalidade de acumular riqueza por meio da produção do trabalho excedente. Por outro lado, reafirmamos o trabalho enquanto ponto central e ontológico nas sociedades humanas, pois "sem trabalho não há humanidade" (GUIMARÃES, 2014, p.44) e como bem destaca este autor, o trabalho docente se localiza como fração do trabalhador coletivo, embora "por outro lado evidenciamos que na sociedade capitalista o trabalho deve ser reduzido à mercadoria para que possa produzir mais-valia" e isso pressupõe, organicamente, processos educacionais voltados para a formação do trabalhador. (GUIMARÃES, 2014, p.44).

Neste estudo a categoria trabalho docente é compreendida a partir do seguinte conceito:

Trata-se de uma categoria que abarca tanto os sujeitos que atuam no processo educativo nas escolas e em outras instituições de educação, nas suas diversas caracterizações de cargos, funções,

TrabalhoNecessário- www.uff.br/revistatrabalhonecessario: ano 16, №29/2018 
tarefas, especialidades e responsabilidades, determinando suas experiências e identidades, quanto às atividades laborais realizadas. O trabalho docente não se refere apenas à sala de aula ou ao processo de ensino formal, pois compreende a atenção e o cuidado, além de outras atividades inerentes à educação. De forma genérica, é possível definir o trabalho docente como todo ato de realização no processo educativo (OLIVEIRA, 2010, p. 1).

Nesta compreensão, ressaltamos que o trabalho docente em EF na EJA traduz a necessidade de uma leitura política sobre as reais condições de trabalho e jornada a ser desenvolvida com jovens e adultos trabalhadores; sobre os processos educativos desenvolvidos com estes sujeitos; sobre a dinâmica da sala de aula e sobre o conjunto de atividades, ações que ocorrem e interferem no trabalho docente em EF na realidade da RMEB.

Partimos da perspectiva que o trabalho docente em EF na EJA envolve a especificidade do binômio Jovens e adultos trabalhadores (as) e Cultura Corporal, evidenciando o direito à educação destes que vivem do próprio trabalho (VENTURA, 2008), integrantes da classe-que-vive-do-trabalho (ANTUNES, 2005) e que como possibilidade histórica de humanização para a classe trabalhadora, a EF e Cultura Corporal apresenta-se nos espaços escolares e sociais como uma síntese científica e filosófica para o enfrentamento à lógica do modo de produção vigente (FRIZZO, 2012).

A EJA representa um campo político da educação que integra enquanto sujeitos históricos e culturais, o conjunto de jovens e adultos, docentes e todos (as) os (as) demais membros da classe trabalhadora que atuam com esta modalidade da educação direta ou indiretamente, nos espaços sociais da contemporaneidade e que de forma histórica e dialética vem lutando pelo direito, acesso e permanência à educação pública, socialmente referenciada na sociedade. Compreendemos, ainda, que este campo político agrega a diversidade da classe trabalhadora, quer seja mulheres e homens, trabalhadores e trabalhadoras, jovens, sujeitos do campo, da cidade que pautam suas lutas históricas pelo acesso da produção material e imaterial acumulada historicamente pela humanidade.

\section{As condições e jornada de trabalho em EF na EJA da Rede Municipal de Ensino de Belém-PA}


Após a breve análise sobre o trabalho docente em EF na EJA, inclinamonos agora sobre a questão das condições e jornada de trabalho na RMEB, na tentativa de compreender como está configurado este trabalho com jovens e adultos trabalhadores, frente a conjuntura da sociedade capitalista.

De acordo com Frizzo (2012), a questão condição de trabalho vem sendo amplamente discutida no campo científico com estudos que apontam críticas à organização atual da escola e por aqueles que sinalizam a defesa de educação a partir do modelo hegemônico como caminho objetivo para a construção de políticas para o campo da educação e trabalho do professor.

Compreendemos que as condições de trabalho e jornada de trabalho são um dos elementos de mediação que implicam no campo do trabalho docente em EF e que para além destes desdobramentos também impactam na formação do (a) jovem e adulto trabalhador (a) da EJA.

Kuenzer e Caldas (2009, p. 31) definem as condições de trabalho como o "conjunto de recursos que possibilita uma melhor realização do trabalho educativo e que envolve tanto a infraestrutura das escolas, os materiais didáticos disponíveis, quanto os serviços de apoio aos educadores e à escola".

O conceito de condições de trabalho está intimamente vinculado às condições de vida dos trabalhadores e que "a necessidade de assegurar melhores condições de trabalho é uma luta contínua para a qual os trabalhadores não poderão ceder ao movimento de acumulação do capitalismo sem resistir continuamente" (OLIVEIRA e VIEIRA, 2012, p. 156).

As condições de trabalho dão suporte ao exercício do trabalho docente na escola e, consequentemente, ao amplo acesso às experiências e conhecimentos acumulados historicamente pela humanidade no campo da EF, por outro lado também aponta os perigos de adoecimento e condições de segurança nos ambientes educacionais, tanto para os (as) docentes como para estudantes e demais sujeitos que integram a realidade escolar. As condições de trabalho compreendem também,

[...] aspectos relativos à forma como o trabalho está organizado, ou seja, a divisão das tarefas e responsabilidades, a jornada de trabalho, até as formas de avaliação de desempenho, horários de trabalho, procedimentos didático-pedagógicos, admissão e administração das carreiras docentes, condições de remuneração, entre outras. A divisão social do trabalho, as formas de regulação,

TrabalhoNecessário- www.uff.br/revistatrabalhonecessario: ano 16, №29/2018 
controle e autonomia no trabalho, estruturação das atividades escolares, a relação de alunos por professor, também podem ser compreendidas como componentes das condições de trabalho docente (OLIVEIRA e VIEIRA, 2012, p. 157)

Aos sujeitos docentes solicitamos que respondessem questões relacionadas às condições de trabalho na entrevista relacionando à unidade educacional que atuam com a EJA. Eles apontaram suas críticas e problematizações sobre as condições do trabalho docente na EF, como mostramos nos seguintes excertos:

Quanto à infraestrutura, devido à situação da quadra e do telhado quebrado, se fores olhar tá todo molhado a quadra e a vizinhança corre em cima da telha da quadra atrás de papagaio ou fugindo da polícia; não sei; aí quebram. A quadra tá sem iluminação por quê? Porque roubaram o refletor. Quer dizer... imagina a comunidade roubar o material que é pra eles usarem, né (PROFESSOR EMANUEL).

Infraestrutura, eu tenho uma certa infraestrutura por ter uma quadra, mal iluminada e mal preservada também, material pedagógico é muito insuficiente e mesmo solicitando o material, dificilmente chega da maneira que eu gostaria, os equipamentos na escola, eles não são voltados para atividades de EF, normalmente eu tenho dificuldade de conseguir alguns equipamentos. $E$ os recursos financeiros eu não vejo sendo voltados para a prática da atividade física dentro da disciplina de EF (PROFESSOR RUY).

A quadra vai para o fundo, entendeu? No período de chuva, fica tudo alagado e quando tem sol, um calor terrível. O tempo da aula de 40 minutos também não ajuda. Pra gente começar o trabalho já está na hora de voltar para começar o resto das aulas (PROFESSORA JOANA).

Essas situações que norteiam o trabalho docente em EF na EJA expressam aspectos de insatisfação, o que agudiza a docência no espaço escolar. Em relação a isso o professor Emanuel destaca "quando a quadra está molhada eu não levo os alunos, por que? Eles podem escorregar no chão molhado, podem cair e quebrar a cabeça, um braço, eu não levo. Fico na sala de aula e explico que a culpa não é minha". Já o professor Raimundo aprofunda suas reflexões sobre as condições de trabalho que enfrenta na escola relatando que: "Infraestrutura e material pedagógico é ridículo. Tem escolas com somente bolas furadas, as quadras são mal feitas para uma cidade que chove todo dia, toda vez 
a quadra alaga, quando não tá alagada, não tem rede ou algo tá quebrado na quadra, demora demais pra consertar as coisas".

Fica evidente nas falas que as condições de trabalho impedem 0 desenvolvimento do trabalho docente com os (as) jovens e adultos trabalhadores na escola. Os docentes apontam que a má iluminação do espaço escolar como um todo e da quadra no ensino noturno inviabilizam a promoção de experiências corporais nas aulas, condicionando o uso exclusivo da sala de aula para as aulas de EF. A RMEB possui 199 escolas municipais e somente 68 escolas possuem quadra esportiva.

Do conjunto de situações mencionadas acima, identificamos outro elemento que está ligado à condição de trabalho, a aquisição por conta própria de materiais pedagógicos para as aulas. Os docentes testemunham:

A dificuldade eu resolvo do meu bolso, quando não há possibilidade na escola, eu não vou parar meu trabalho, meu planejamento, eu uso meus recursos próprios. Compro o material desde quando eu iniciei o meu trabalho. Se for fazer uma culminância, a escola não garante todo o material, sempre os professores entraram com seus recursos, e isso também ocorre na EF (PROFESSOR ANDRÉ).

O material que eu utilizo é material próprio, que eu levo de escola pra escola, saio de uma escola e levo meu material pra outra escola porque o material é meu (PROFESSOR RUY).

Com relação a material pedagógico alguns eu confeccionava, comprava material e construía material mesmo, pesquisava, fazia atividades de leituras, mas relacionadas a EF, caça palavras e joguinhos para conseguir levar o trabalho (PROFESSORA LEILA).

A busca pela qualidade do trabalho, mesmo com todos os desafios e contradições encontrados na escola pública, tem movido os docentes a solucionarem as necessidades materiais da escola retirando de seu próprio salário para a compra de materiais pedagógicos necessários às aulas. Ao mesmo tempo, é necessário reconhecer que o trabalho, no capitalismo, passa a ser gerador da condição alienante "[...] e degradação humana à medida que esses homens se veem obrigados a reproduzir suas condições de existência vendendo sua força de trabalho em troca de um salário" incompatível com condições dignas de sobrevivência (MEDEIROS \& REIS, 2012, p. 76). 
$\mathrm{Na}$ tentativa de produzir novas experiências educativas na EJA, os docentes de EF se esbarram com a falta de recursos. Para o professor Raimundo,

\begin{abstract}
O grande problema que a gente tem em aliar a tecnologia ao nosso trabalho é justamente a falta de recursos, pouquíssimas escolas do Município têm internet, quando tem internet não tem computador, quando tem computador não tem data show, quando tem data show não tem a sala para ministrar a aula. Então, a gente fica resumido ao pincel atômico e ao quadro, se você quer fazer um trabalho melhor, você leva o computador pra escola e ao mesmo tempo você corre o risco de ser assaltado.
\end{abstract}

Oliveira e Assunção (2010) consideram que as condições de trabalho designam o conjunto de recursos que possibilitam a realização do trabalho, envolvendo as instalações físicas, os materiais e insumos disponíveis, os equipamentos e meios de realização das atividades e outros tipos de apoio necessários, dependendo da natureza da produção.

A análise dos dados sobre as condições de trabalho nos indica um cenário preocupante em que urgem medidas que possam garantir as condições necessárias e dignas para o desenvolvimento da docência da EF na EJA, que também se estende ao conjunto de ensino da realidade escolar. Imperioso, também, torna-se o empoderamento do docente enquanto um intelectual, um sujeito histórico com condições para a construção de possibilidades teóricometodológicas para as aulas na escola, uma leitura crítica sobre as correlações de forças para a construção da autonomia docente, para a construção de um currículo que ajude na formação crítica e emancipadora dos jovens, adultos e idosos.

As falas dos docentes supracitadas apontam o descaso, o desmonte da escola pública, o esvaziamento de condições dignas para a realização do trabalho docente em EF. A existência da quadra é um elemento importante para o conjunto de práticas pedagógicas que podem ser realizadas na EF na escola, mas as condições em que a quadra se encontra juntamente com e os materiais pedagógicos são fundamentais para o desenvolvimento do trabalho docente.

Em concordância com Oliveira e Assunção (2010, p. 1), é pertinente considerarmos que as condições de trabalho são derivadas da forma determinada pela organização do trabalho no capitalismo, e que 
[...] as condições de trabalho não se restringem ao conjunto de meios necessários à realização de uma atividade, mas contemplam relações específicas de exploração, já que o processo de trabalho no capitalismo é o meio pelo qual matériasprimas e insumos são transformados em produtos, constituindose, ao mesmo tempo, em processo de produção de valor. É justamente por essa dupla função que o processo de trabalho é considerado o lócus da exploração capitalista e relação fundamental do mesmo.

Esta ideologia implica uma sobrecarga de trabalho, de responsabilidades para o docente, imprimindo neste o sentimento de fracasso por não dar conta dos dilemas da escola pública, dos desafios da sala de aula e das atribuições que the são impostas no cotidiano da escola. As demandas do sistema educacional brasileiro impõem uma responsabilidade grandiosa, intensa e incoerente/contraditória para o trabalho docente, trazendo para o docente de EF, além da materialidade do trabalho pedagógico, uma impressão de que "precisa dar conta" das práticas da cultura corporal para os jovens e adultos trabalhadores da EJA. As condições objetivas deste trabalho reforçam uma lógica que culmina no adoecimento do docente, pois resistir à lógica do capital é desafio complexo e sub-humano na conjuntura do capitalismo.

A jornada de trabalho é um elemento que também impacta o trabalho docente em EF na EJA, cuja modalidade de educação é utilizada pelos docentes para completar a carga horária de trabalho, outro aspecto que sinaliza o aumento da jornada de trabalho em EF. A cultura docente em EF na EJA tem se materializado como um incremento à carga horária, ocorrendo um "jogo de disputa" entre os docentes para o complemento de suas rendas.

Segundo Dal Rosso (2010, p. 1) a jornada de trabalho é caracterizada pelo "tempo gasto pelo indivíduo em atividade laboral durante o dia, semana, mês, ano ou vida". Para esta concepção, que estabelece "o critério de trabalho como parâmetro, a vida de um indivíduo pode ser dividida entre tempo gasto em trabalho e tempo gasto na realização de outras atividades" (id., ibid.).

Os sujeitos docentes em EF apontam algumas características sobre a jornada de trabalho na EJA:

A EJA tem uma carga horária muito reduzida, o professor ele tem que se deslocar muito para conseguir suprir uma carga horária mínima que possa ser satisfatória financeiramente. Tem que ter

TrabalhoNecessário- www.uff.br/revistatrabalhonecessario: ano 16, №29/2018 
muitas turmas, tem que ter muitas escolas diferentes e consequentemente a qualidade do trabalho cai e não consegue ter uma qualidade ideal. Me sinto cansado, me sinto desgastado e não era a ideia que eu tinha quando entrei na Rede. (PROFESSOR RUY).

É muito cansativo, é muito desgastante. O professor de EF trabalha [em] três ou quatro escolas, pega carro pra ir pra uma, pega carro pra ir pra outra e, quando tem carro próprio, tem quatro festas juninas pra dar conta, tem que ensaiar quinze turmas pra se apresentar, a gente fica sobrecarregado e acaba não se identificando com as escolas, por que a gente pisa na escola [e] sai de novo, isso não favorece. Minha saúde que nesses três anos que tô na EJA, tenho só 29 anos, já passei três vezes por diagnóstico de estafa. Porque dar aula no Jurunas, vou pro Guamá, vou pra Terra Firme no mesmo dia. A gente é refém da $\mathrm{HP}$, eu não posso montar meu horário, sou refém da HP da professora aqui (PROFESSOR RAIMUNDO).

Em relação à jornada de trabalho, Oliveira (2004) afirma que as mudanças decorrentes das reformas educacionais têm resultado na intensificação do trabalho docente, na ampliação do seu raio de ação e, consequentemente, em maiores desgastes e insatisfação por parte desses trabalhadores. Ainda para a mesma autora, o fato de o docente ter de assumir na escola pública múltiplas funções que não são próprias de sua formação profissional implica diretamente o processo de precarização do trabalho docente.

\begin{abstract}
Muitos docentes também se submetem a horas de trabalho não pago na preparação de aulas, correção de provas, no atendimento a familiares dos alunos e em atividades coletivas nas escolas. A jornada é uma questão relevante por uma razão adicional, a saber, a luta pelo tempo livre. Dispor de tempo livre significa alargar o espaço de escolhas e de decisão para realizar atividades edificantes (DAL ROSSO, 2010, p. 1).
\end{abstract}

Durante a pesquisa, indagamos o que os sujeitos docentes consideram sobre seu trabalho. O resultado apontou que 90\% dos docentes entrevistados caracterizam o trabalho como desgastante, desafiador, desvalorizado e repetitivo e $10 \%$ apontam como prazeroso e dinâmico.

Tais razões ocasionam o processo de intensificação do trabalho docente, considerado por Del Pino, Vieira e Hypólito (2009) como consequência das novas mudanças no processo de trabalho escolar e nas políticas educativas recentes, 0 que indica que a tese da intensificação vem apresentando cada vez mais um 
efeito esmagador no trabalho docente. Os autores conceituam o processo de intensificação levando em conta os seguintes aspectos: a) conduz à redução do tempo de descanso na jornada de trabalho; b) implica falta de tempo para atualização e requalificação em habilidades necessárias; c) implica uma sensação crônica de sobrecarga de trabalho (mais e mais para ser feito em um tempo cada vez menor para fazer o que deve ser feito), o que reduz áreas de decisão pessoal, envolvimento e controle sobre planejamento, aumenta a dependência de materiais e especialistas externos ao trabalho, provocando maior separação entre concepção e execução, entre planejamento e desenvolvimento, dentre outros.

A EF na EJA se constitui do tempo de 30 a 40 minutos, sendo para as turmas de $1^{\underline{a}}$ e $2^{\underline{a}}$ totalidade, 2 (duas) vezes na semana e 1 (uma) vez por semana para $3^{\mathrm{a}}$ e $4^{\mathrm{a}}$ totalidade (CME, 2011). Os docentes apontam o desafio da diminuta carga horária da disciplina EF na EJA, explicitam que este é um elemento que também impacta no trabalho docente na escola.

À noite, tenho 40 minutos para trabalhar, alguns alunos chegam atrasados. Os alunos reclamam do tempo de aula, mas eu não posso fazer nada, isso é muito prejudicial. Tenho que simplificar minha aula, às vezes nem bem consigo organizar a turma, a aula termina (PROFESSOR RAIMUNDO).

Para a $1^{\text {a }}$ e $2^{\text {a }}$ totalidade, trabalham com duas aulas semanais e $3^{\text {a }}$ e $4^{\text {a }}$ totalidade, com uma aula somente, o que corresponde à 5 horas cada aula. Com a redução do tempo da hora aula, no turno da noite para 35, 40 minutos, praticamente inviabiliza um trabalho adequado (PROFESSOR JAIR).

O curto tempo da aula já consegue frustrar o profissional na atividade que ele gostaria de exercer e [na] atividade que ele efetivamente acaba exercendo (PROFESSOR RUY).

Os aspectos apontados pelos professores demonstram a condição objetiva e subjetiva do trabalho docente no que tange ao espaço e tempo da aula e ao sentimento sobre seu trabalho. O professor Tadeu, destaca que: "A minha disciplina tem um histórico prático, mas também tem uma riqueza muito grande teórica, então pelo fato de ser apenas trinta e cinco minutos por semana de aula, essa parte prática fica prejudicada. $\mathrm{O}$ fato de você ter uma carga horária muito curta dificulta você colocar em prática até mesmo assuntos que você viu em sala" 
Notamos que o processo de precarização tem ocorrido tanto para o campo do trabalho docente quanto para o processo de formação humana dos jovens e adultos trabalhadores (as) da EJA, quando o trabalho educativo não tem proporcionado o alcance de seu objetivo sobre o debate e socialização da Cultura Corporal e, suas diversas manifestações com o mundo do trabalho da classe trabalhadora. No quadro a seguir, apresentamos as características do regime de trabalho docente dos sujeitos entrevistados:

Quadro I: Regime de Trabalho dos docentes de EF

\begin{tabular}{|c|c|c|c|c|}
\hline $\begin{array}{c}\text { Professor/ } \\
\text { a }\end{array}$ & $\begin{array}{c}\text { Regime de } \\
\text { Trabalho na } \\
\text { RMEB }\end{array}$ & $\begin{array}{c}\text { Quantas } \\
\text { escolas } \\
\text { trabalha na } \\
\text { RMEB }\end{array}$ & $\begin{array}{c}\text { Quanto tempo } \\
\text { trabalha na } \\
\text { unidade } \\
\text { educacional }\end{array}$ & $\begin{array}{c}\text { Regime de Trabalho } \\
\text { em outros espaços }\end{array}$ \\
\hline Emanuel & 40 horas & 2 escolas & 25 anos & $\begin{array}{c}20 \mathrm{~h}-\text { rede estadual } \\
\text { de ensino (Ciências) }\end{array}$ \\
\hline Ruy & 25 horas & 3 escolas & $\begin{array}{c}3 \text { anos e } 2 \\
\text { meses }\end{array}$ & - \\
\hline André & 20 horas & 2 escolas & 15 anos & $\begin{array}{c}40 \mathrm{~h}-\text { rede estadual } \\
\text { de ensino (EF) }\end{array}$ \\
\hline Raimundo & 30 horas & 3 escolas & 3 anos & $\begin{array}{c}20 \mathrm{~h}-\text { rede estadual } \\
\text { de ensino } \\
\text { (Educação Especial) }\end{array}$ \\
\hline Jair & 20 horas & 1 escola & 3 anos & $\begin{array}{c}\text { 20h- rede estadual } \\
\text { de ensino (EF) }\end{array}$ \\
\hline Tadeu & 15 horas & 2 escolas & 2 anos & $\begin{array}{c}40 \mathrm{~h} \text {-Academia } \\
\text { Atualmente } \\
\text { aposentada-rede } \\
\text { estadual de ensino } \\
\text { (EF) }\end{array}$ \\
\hline Joana & 20 horas & 2 escolas & 19 anos & \\
\hline Leila & 40 horas & 3 escolas & 6 anos & \\
\hline
\end{tabular}

Fonte: Elaborado pela autora

Do conjunto dos docentes entrevistados a maior parte $(75 \%)$ tinha uma jornada de trabalho igual ou superior a 40 horas semanais, exceto uma docente que atua somente na Rede Municipal e outra docente que alcançou a aposentadoria em outra rede de ensino. O professor Emanuel por ter uma segunda formação (Licenciatura e Bacharelado em Biologia) atua em outra Rede de ensino com o ensino de Ciências, já o professor Raimundo por ter PósGraduação em Educação Especial foi aprovado em um concurso específico para Educação Especial na Rede Estadual de Ensino, no município de Belém. 
A justificativa dos docentes por uma ampla jornada de trabalho é a condição objetiva devido aos baixos salários na Rede Municipal de Ensino de Belém-PA. A árdua jornada envolvendo não somente as redes públicas de ensino de Belém, mas outros espaços sociais como academias, constituem um contexto de intensificação do trabalho docente, tendo em vista a necessidade objetiva de sobrevivência.

Os docentes apresentam preocupações com relação a desgastante jornada de trabalho. O professor Tadeu destaca que: "O maior empecilho na verdade é você colocar em prática uma aula bem elaborada com essa carga horária semanal de trabalho". O professor Jair, relaciona que: "É uma carga horária grande pela quantidade de turmas, pela quantidade de pessoas que eu encontro durante a semana. Porque se fosse as mesmas 40 horas, mas com uma quantidade menor de turmas, a possibilidade do trabalho poderia fluir melhor"

O conjunto de aspectos apresentados acima aponta para um processo de precarização do trabalho docente (MARIN, 2010) decorrente das mudanças do trabalho e encontramos flexibilização; intensificação; desprofissionalização; degradação; sobrecarga; cobranças; fragilização; desvalorização; competitividade; condições de trabalho e de pesquisa; perda de autonomia; ausência de apoio à qualificação; e, ainda, algumas especificações da esfera pedagógica, tais como valorização do saber da experiência em detrimento do pedagógico; ação docente pouco sólida em termos de conhecimento; envolvimento dos professores em trabalhos burocráticos, cansaço excessivo; sofrimento; desistência; resistência; adoecimento; isolamento dentre outros.

O professor Jair menciona que o processo de condição e jornada de trabalho impacta no seu trabalho tanto objetivo quanto subjetivamente:

Vou pegar um exemplo, um problema que é meu, problema pessoal e que tem implicações práticas, que é a questão do planejamento geral e do plano de aulas que eles ocorrem de uma forma bem informal com um caderno que eu costumo usar, que são meus cadernos de anotações, diário de bordo, ou eles passam estritamente pela cabeça. Amanhã vou trabalhar com a turma tal e eu vou trabalhar isso, isso e isso, o que cria debilidades importantes, né? De pensar nos recursos, de pensar nas especificidades da turma. Então, embora eu opte por trabalhar com um referencial crítico, que propõe a transformação social, a partir dos elementos reais que são impostos, tudo isso acaba 
interferindo e sobrepõe minhas escolhas, mesmo políticas, isso me causa angústia.

As condições e jornada de trabalho têm aumentado assustadoramente a precarização do trabalho docente (HYPOLITO, 2012) e é inegável o aumento da carga de trabalho por parte dos docentes entrevistados, bem como seus desdobramentos na subjetividade docente, como vimos no depoimento do Professor Jair. Coadunamos com Hypolito (2012, p. 227) quando afirma que: "Não se pode falar em educação de qualidade, porquanto as condições de produção do trabalho de ensinar persistam precárias".

Os elementos traçados acima apontam mudanças e implicações no processo de trabalho na escola básica de forma objetiva e subjetiva, o que afeta a identidade docente em EF na EJA e na formação humana de jovens e adultos trabalhadores da escola pública. Sobre esses aspectos Frizzo (2012, p. 104) destaca que para o contexto da escola capitalista é imprescindível a existência destas "caracterizações precárias para que a formação pretendida por ela seja alcançada".

Ou seja, para formar um ser humano de maneira flexível e abstrata a partir da lógica do mercado e adaptável a qualquer situação decorrente da instabilidade e volatilidade do atual quadro de desemprego estrutural é preciso que a "qualidade" do ensino seja balizada pela resposta que os indivíduos dão frente a este quadro (FRIZZO, 2012, p. 104).

As precárias condições de trabalho encontradas nas escolas vêm evidenciando o avanço do desmonte da escola pública, com o esvaziamento de condições dignas para a realização do trabalho docente. A jornada de trabalho tem se caracterizado como um processo desgastante da ação docente e, em muitas situações, os trabalhadores em EF encontram-se em estado de insatisfação, desmotivação e desvalorização de seu trabalho no contexto da educação básica da Rede Municipal de Ensino de Belém-PA.

\section{Considerações transitórias}

O conjunto de elementos apresentados neste estudo nos possibilita evidenciar o processo de precarização que o trabalho docente em EF na EJA se 
encontra. Os trabalhadores de EF apresentaram elementos de desgaste, desmotivação e insatisfação no trabalho, pois há um processo de degradação intenso e de desrealização do ser social (ANTUNES, 2005), como vimos nos depoimentos dos docentes.

As condições e jornada de trabalho têm se caracterizado como aspectos que medeiam a configuração de um trabalho precário e intensificado, contraditoriamente os docentes vêm resistindo e apontam a relevância da EF como contributo social e histórico para a formação dos jovens e adultos trabalhadores da modalidade de educação, EJA.

Notamos, assim, um processo histórico no qual os docentes em EF vêm enfrentando, nas condições de trabalho, na jornada de trabalho e em tantos outros campos, exclusão, desvalorização e invisibilidade do componente curricular na formação humana na escola pública, que implicam baixo nível de qualidade do trabalho docente e aprofundam a precarização deste trabalho na realidade da EJA da RMEB.

A falta de condições objetivas que possibilitem a realização de um trabalho de qualidade em EF na EJA afeta também as condições subjetivas de trabalho em EF. Isso se agrava pela dificuldade de estabelecer relações com a diversidade sociocultural encontrada na EJA; ausência de gestão democrática na escola; ausência de acompanhamento pedagógico para os docentes e estudantes da EJA, entre outros elementos que contribuem para o mal-estar docente em EF.

\section{Referências}

ANTUNES, Ricardo. O Caracol e sua concha: ensaios sobre a nova morfologia do trabalho. São Paulo: Boitempo Editorial, 2005.

BARDIN, Laurence. Análise de Conteúdo. Lisboa: Edições 70. 2011.

CONSELHO MUNICIPAL DE EDUCAÇÃO. Resolução № 020/11-CME. Diretrizes para a Estrutura Curricular da Educação de Jovens e Adultos nas escolas mantidas pela Secretaria Municipal de Educação. Belém, maio 2011.

DAL ROSSO, S. Jornada de trabalho. In: OLIVEIRA, D.A.; DUARTE, A.M.C.; VIEIRA, L.M.F. DICIONÁRIO: trabalho, profissão e condição docente. Belo Horizonte: UFMG/Faculdade de Educação, 2010. CDROM 
DEL PINO, M.A.B.; VIEIRA, J.S.; HYPOLITO, A.M. Trabalho docente, controle e intensificação: câmeras, novo gerencialismo e práticas de governo. In: FIDALGO, Fernando; OLIVEIRA, M. A. M.; FIDALGO, Nara L. Rocha. A intensificação do trabalho docentes: tecnologias e produtividade. Campinas: Papirus, 2009.

DUARTE, Adriana. Políticas educacionais e o trabalho docente na atualidade: tendências e contradições. In: OLIVEIRA, Dalila; DUARTE, Adriana. Políticas públicas e educação: regulação e conhecimento. Belo Horizonte: Fino Traço, 2011.

FRIGOTTO, Gaudêncio. Trabalho. In: OLIVEIRA, D.A.; DUARTE, A.M.C.; VIEIRA, L.M.F. DICIONÁRIO: trabalho, profissão e condição docente. Belo Horizonte:

UFMG/Faculdade de Educação, 2010. CDROM.

FRIZZO, Giovanni F. E. A Organização do Trabalho Pedagógico da Educação Física na Escola Capitalista. 2012. 264f. Tese (Doutorado em Ciências do Movimento) - Universidade Federal do Rio Grande do Sul, Porto Alegre.

GUIMARÃES, André Rodrigues. Trabalho Docente Universitário: participação dos professores na materialização da contrarreforma da educação superior na UFPA. 2014. 285f. Tese (Doutorado em Educação) - Universidade Federal do Pará. Belém.

HARVEY, David. Condição Pós-Moderna: uma pesquisa sobre as origens da mudança cultural. Tradução Adail U. Sobral; Maria Stela Gonçalves. São Paulo: Edições Loyola. 2014.

HYPOLITO, A. L. M; VIEIRA, J.S. Reestruturação educativa e trabalho docente: autonomia, contestação e controle. In: HYPOLITO, A. L. M; VIEIRA, J.S.; GARCIA, M. M. A. Trabalho docente: formação e identidade. Pelotas: Seiva, 2002.

HYPOLITO, A. L. M. Trabalho docente na educação básica no Brasil: as condições de trabalho. In: OLIVEIRA, D. A.; VIEIRA, L. F. (org.). Trabalho docente na educação básica: a condição docente em sete estados brasileiros. Belo Horizonte: Fino Traço, 2012.

KUENZER, Acácia Z; CALDAS, Andrea. Trabalho docente: comprometimento e desistência. In: FIDALGO, Fernando; OLIVEIRA, M. A. M.; FIDALGO, Nara L. Rocha. A intensificação do trabalho docentes: tecnologias e produtividade. Campinas: Papirus, 2009.

MARIN, A.J. Precarização do trabalho docente. In: OLIVEIRA, D.A.; DUARTE, A.M.C.; VIEIRA, L.M.F. DICIONÁRIO: trabalho, profissão e condição docente. Belo Horizonte: UFMG/Faculdade de Educação, 2010. CDROM

MARX, K. Processo de Trabalho e Processo de Valorização. In: ANTUNES, Ricardo. A Dialética do trabalho: escritos de Marx e Engels. São Paulo: Expressão Popular, 2013. 
MEDEIROS, L.; REIS, M. IZABEL A. Condições de trabalho e efeitos sobre a saúde dos docentes. In: MAUÉS, O. C.; CAMARGO, A.; OLIVEIRA, D.A.; VIEIRA, L. F. O trabalho docente na educação básica: o Pará em questão. Belo Horizonte: Fino Traço, 2012.

OLIVEIRA, D. A. Trabalho docente. In: OLIVEIRA, D.A.; DUARTE, A.M.C.; VIEIRA, L.M.F. DICIONÁRIO: trabalho, profissão e condição docente. Belo Horizonte: UFMG/Faculdade de Educação, 2010. CDROM.

A reestruturação do trabalho docente: precarização e flexibilização. Educação \& Sociedade. V 25, n.89, Set/dez, 2004.

OLIVEIRA, D. A.; VIEIRA, L. F. Condições de trabalho docente: uma análise a partir dos dados de sete estados brasileiros. In: (org.). Trabalho docente na educação básica: a condição docente em sete estados brasileiros. Belo Horizonte: Fino Traço, 2012.

OLIVEIRA, D.A.; ASSUNÇÃO, A.A. Condições de trabalho docente. In: OLIVEIRA, D.A.; DUARTE, A.M.C.; VIEIRA, L.M.F. DICIONÁRIO: trabalho, profissão e condição docente. Belo Horizonte: UFMG/Faculdade de Educação, 2010. CDROM

SEGEP. Anuário Estatístico do Município de Belém. 2012. Belém: Secretaria Municipal de Coordenação Geral do Planejamento e Gestão, 2012.

SOARES, Carmen L. et al. Metodologia do ensino da EF. São Paulo: Cortez, 1992.

VENTURA, J. P. Educação de Jovens e Adultos ou Educação da Classe Trabalhadora? Concepções em disputa na contemporaneidade brasileira. 2008. 302f. Tese (Doutorado em Educação) - Universidade Federal Fluminense. Niterói.

Recebido em: 29 de novembro de 2017. Aprovado em: 29 de março de 2018. Publicado em: 13 de junho de 2018. 